19

\title{
Плазмонная активация и тушение люминесценции растворов полифениленвинилена (MEH-PPV) одно- и двустенными углеродными нанотрубками
}

\section{(C) М.Г. Кучеренко, В.Н. Степанов, Н.Ю. Кручинин}

Центр лазерной и информационной биофизики, Оренбургский государственный университет, 460018 Оренбург, Россия

e-mail: clibph@yandex.ru

Поступила в редакцию 02.04.2020 г.

В окончательной редакции 02.04.2020 г.

Принята к публикации 15.04.2020 г.

Исследованы спектрально-люминесцентные свойства бензольных и толуольных растворов poly[2-methoxy, 5-(2'-ethylhexyloxy)-1,4-phenylene-vinylene] (MEH-PPV) с добавками одно- и двустенных углеродных нанотрубок (УНТ) с целью обнаружения проявлений плазмонных свойств УНТ в люминесценции растворов МЕНPPV. Установлено, что зависимость интенсивности люминесценции полимерного раствора от концентрации УНТ носит немонотонный характер: с увеличением количества растворенных нанотрубок эта интенсивность вначале возрастает, а затем спадает. При этом деформация самого спектра свечения практически не имеет места. Эффект наблюдался как при использовании одностенных УНТ (ОУНТ), так и двустенных (ДУНТ). Глубина модуляции интенсивности свечения в случае ДУНТ была выше, чем в случае ОУНТ. Для объяснения наблюдаемых зависимостей предложены различные варианты электродинамической модели активациитушения люминесценции MEH-PPV углеродными нанотрубками. Произведено прямое моделирование характеристик ближнего и дальнего поля на основе уравнений Максвелла, для численного решения которых использовался метод конечных разностей во временной области (FDTD). Проведенными вычислительными экспериментами было установлено, что УНТ со слоем MEH-PPV обладают направленными антенными свойствами, выступая в роли своеобразных волноводов. Так, энергия излучения, достигшего дальней зоны, в направлении оси нанотрубки оказалась на порядок выше, чем в случае раствора без УНТ. Обнаружены электромагнитные волны фонтанного типа, исходящие из обоих концов нанотрубки, а также стадия биений плазмонных волн, характеризующая нанотрубку как волновод. Выполнено молекулярно-динамическое моделирование конфигураций адсорбированной цепи MEH-PPV в различных растворителях как на отдельной УНТ, так и на двух параллельных УНТ с вариацией расстояния между ними. Установлено, что по мере увеличения расстояния между УНТ конформационная структрура МЕН-PРV становится все более рыхлой: наблюдается увеличение числа крупных петель макроцепи в объемной фазе раствора.

Ключевые слова: молекулярная люминесценция, углеродная нанотрубка, плазмон-поляритонная волна, макромолекулярная цепь.

DOI: $10.21883 /$ OS.2020.08.49734.126-20

Фотопроцессы в полупроводниковых полимерных композитах по-прежнему представляют значительный интерес для многочисленных исследователей и специалистов-практиков в области электроники, солнечной энергетики и систем переработки и хранения информации [1]. Полимерные гибридные наноструктуры различного строения могут найти применение при разработке элементной базы современной и будущей органической наноэлектроники. Полученные в последние годы рядом авторов результаты дают основания для успешного использования исследованных композитных полимерных структур с возможностями модифицирования их электронных свойств при разработке эффективных фотовольтаических ячеек и селективных химических сенсоров [2]. Полифениленвинилен использовался в качестве эмиссионного слоя в первых полимерных светоизлучающих диодах, а также как электронодонорный материал в органических солнечных элементах [2,3]. Небольшая оптическая ширина запрещенной зоны и ярко-желтая флуоресценция делает MEH-PPV кандидатом на внедрение в такие области современной твердотельной электроники, как производство светоизлучающих диодов и фотоэлектронных устройств различной модификации и области применения $[3,4]$. Благодаря термической и механической стабильности этого полимера, технологичности его производства и обработки, а также наличию подходящих электрических и оптических свойств MEH-PPV, вероятнее всего, ожидает широкий спектр использования. Физические и электронные свойства MEH-PPV легко могут быть изменены путем включения в макроцепь функциональных боковых групп.

В настоящей работе объектами исследования являлись бензольные и толуольные растворы полупроводникового органического полимера поли[2-метокси-5-(2'- 
этилгексилокси)- 1, 4-фенилен-винилен]-poly[2-methoxy, 5-(2'-ethylhexyloxy)-1,4-phenylene-vinylene] (MEH-PPV) c добавками одно- и двустенных углеродных нанотрубок (УНT). MEH-PPV - это проводящий полимер из семейства твердотельных полимеров с молекулярным весом $\sim 150000-250000$.

Важнейшим направлением наноэлектроники является исследование электромагнитного отклика нанокомпозитов, а также разработка на их основе различных функциональных материалов и систем, обеспечивающих улучшенные сочетания характеристик разного класса [5]. В частности, использование углеродных нанотрубок в качестве включений при получении полимерных композиционных материалов позволяет существенно влиять на их электромагнитный отклик в требуемых спектральных диапазонах [6].

В предыдущей работе авторов [7] было исследовано влияние углеродных нанотрубок и металлических $(\mathrm{Ni}$, $\mathrm{Co}, \mathrm{Fe}, \mathrm{Cu}, \mathrm{Ag}$ ) наночастиц на безызлучательный перенос энергии электронного возбуждения между молекулами органических красителей (акридиновый оранжевый - донор и нильский синий - акцептор) в спиртовых растворах поливинилбутираля. При определенных концентрациях компонентов смеси было обнаружено это влияние, выражающееся в увеличении интенсивности сенсибилизированной флуоресценции акцептора при одновременном тушении флуоресценции донора. Была предложена простейшая модель процесса, воспроизводящая наблюдаемое перераспределение интенсивностей свечения между спектральными полосами общего спектра, а также выполнены молекулярно-динамические расчеты структуры нанокомпозитов, подтверждающие образование ассоциированных молекулярно-плазмонных комплесов, охваченных макроцепной оболочкой. Схожие модели плазмон-индуцированного межмолекулярного переноса энергии вблизи проводящих цилиндрических объектов развивались в [8-10].

Основной целью настоящей работы являлось обнаружение проявлений плазмонных свойств УНТ в экситонной люминесценции растворов макроцепей МЕНPPV. Углеродные нанотрубки и полифениленвинилен плохо растворяются в воде, поэтому использовались органические растворители: толуол и бензол.

Раствор полифениленвинилена составлял 0.00063 массовых процента, а доля УНТ измерялась в относительном процентном отношении к максимальной концентрации трубок в растворе. УГлеродные нанотрубки массой $0.5 \mathrm{mg}$ разводили в $15 \mathrm{ml}$ растворителя. Затем раствор помещали в ультразвуковую ванну на $2 \mathrm{~h}$ для разделения сцепленных в клубки нанотрубок. После этого производилось центрифугирование смеси с последующим отделением неразведенной части нанотрубок. Для улучшения растворимости нанотрубок в ряде случаев в раствор добавлялся полистирол. Полученные таким образом растворы с разведенной фракцией УНТ использовалась в экспериментах.
Фотоактивация системы осуществлялась различными источниками оптического излучения: твердотельным лазером $\mathrm{Nd}^{3+}$ со светодиодной накачкой (длина волны генерации $\lambda_{m}=532 \mathrm{~nm}$, полуширина линии $10 \mathrm{~nm}$ ), лазерным диодом с длиной волны генерации $\lambda_{\max }=460 \mathrm{~nm}$ и полушириной линии $30 \mathrm{~nm}$, а также твердотельным лазером с длиной волны генерации $\lambda_{m}=445 \mathrm{~nm}$ и полушириной линии $10 \mathrm{~nm}$. Характеристики люминесценции измерялись спектрометром на базе монохроматора МДР 204 и ФЭУ-100. Спектры свечения растворов МЕНPPV с различным содержанием УНТ приведены на рис. 1. Для толуольного раствора основной спектральный максимум свечения приходился на длину волны $555 \mathrm{~nm}$. На рис. 2 представлены концентрационные зависимости интенсивности в максимуме спектров свечения толуольных растворов MEH-PPV с ОУНТ $(a)$ и ДУНТ (b).

Из рис. 1 и 2 видно, что при добавлении в раствор MEH-PPV УНТ в области малых концентраций наблюдалось резкое увеличение интенсивности свечения. При дальнейшем увеличении концентрации как ОУНТ (рис. 2,a), так и ДУНТ (рис. 2,b) происходило нивелирование эффекта „разгорания “ флуоресценции смеси вплоть до ее тушения в случае ДУНТ с полистиролом (рис. 2, $b$, кривая 2).

Таким образом, при фотовозбуждении раствора световыми источниками $(445,460$ и $532 \mathrm{~nm})$ концентрационные зависимости интенсивности люминесценции полимерного раствора носят немонотонный характер: с увеличением доли растворенных нанотрубок интенсивность люминесценции в максимуме спектра сначала возрастает, а затем падает. При этом деформация самого спектра свечения практически не имеет места (рис. 1). Данный эффект наблюдался как при использовании ОУНТ, так и ДУНТ (рис. 1 и 2). Глубина модуляции интенсивности свечения в случае ДУНТ оказалась выше, чем в случае ОУНТ. Аналогичные результаты были получены и при использовании бензола в качестве растворителя. При возбуждении системы светодиодом с длиной волны излучения $460 \mathrm{~nm}$ характер спектров люминесценции незначительно изменялся, но зависимость от концентрации УНТ оставалась прежней. Возможно, что при облучении системы светом с меньшей длиной волны возбуждались дополнительные электронно-колебательные уровни MEH-PPV, инертные при длинноволновой активации, а также высокочастотные плазмонные моды углеродной нанотрубки, что могло изменять характер взаимодействия УНТ с полимером и формировать на выходе незначительно модифицированный спектр люминесценции. В то же время основные спектральные характеристики свечения системы оставались неизменными. 

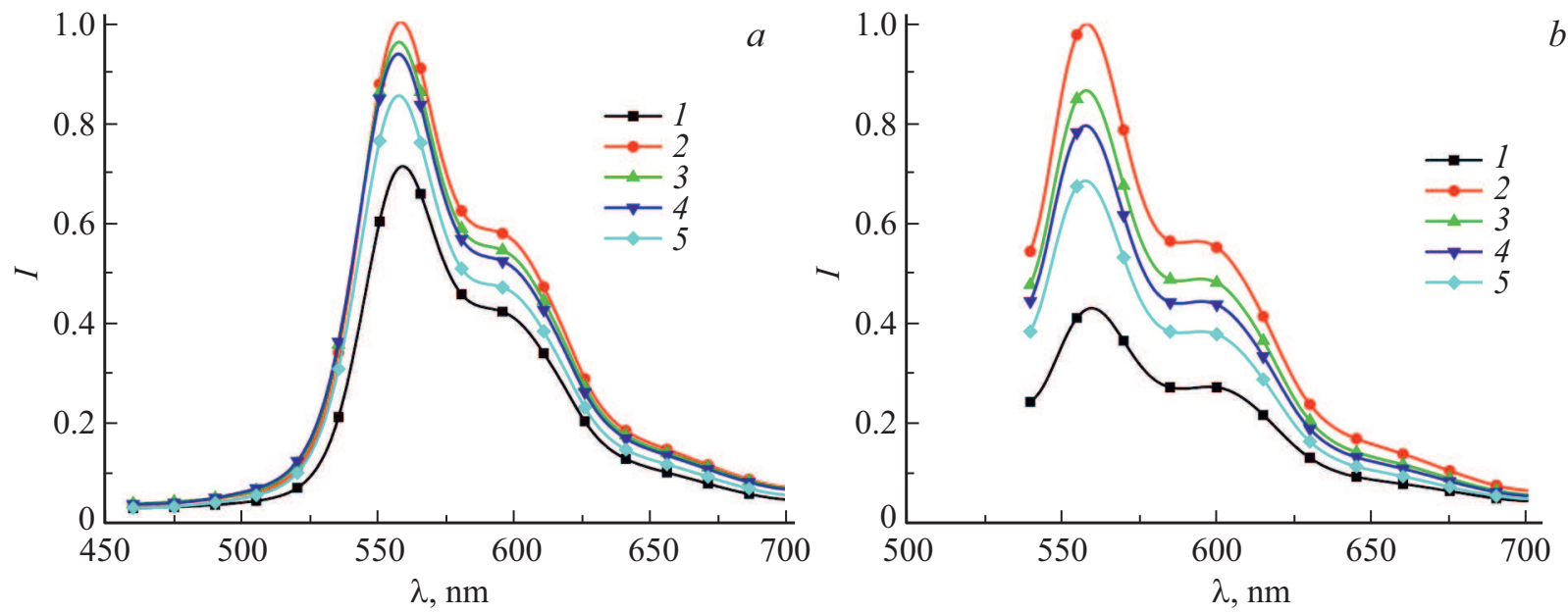

Рис. 1. Спектры люминесценции растворов полифениленвинилена в толуоле с различным содержанием (\%) $(a)$ ОУНТ: $1-0$, $2-6.6,3-13.2,4-19.8,5-100$. (b) ДУНТ: $1-0,2-13.2,3-26.4,4-52.8,5-100$. Возбуждение на длине волны $\lambda_{m}=455 \mathrm{~nm}(a), \lambda_{m}=532 \mathrm{~nm}(b)$.
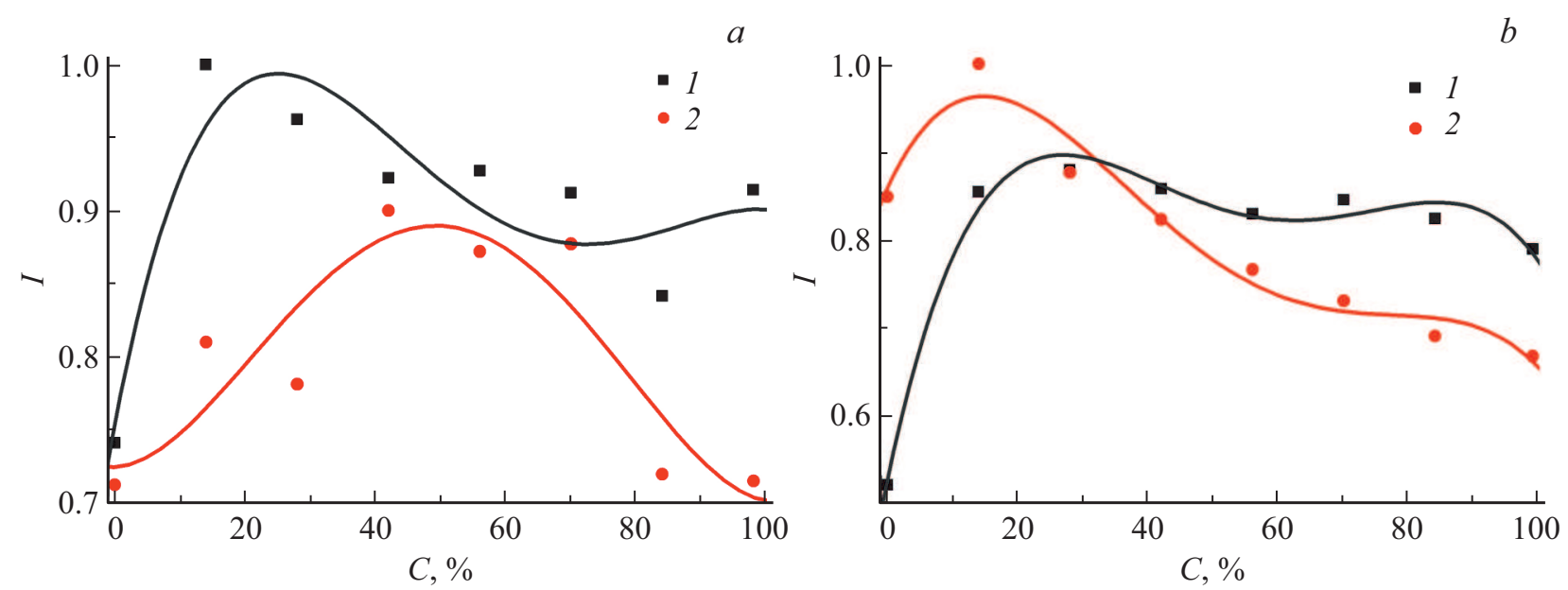

Рис. 2. Концентрационные зависимости интенсивности в максимуме спектра свечения раствора МЕН-PРV с ОУНТ (a) и ДУНТ $(b)$. Зависимости максимумов спектров свечения толуольных растворов полифениленвинилена от концентрации одностенных углеродных нанотрубок (1) и тех же растворов с добавками полистирола (2). Сплошные линии - аппроксимирующие кривые. Возбуждение $\lambda=445 \mathrm{~nm}$.

\section{Электродинамическая модель}

\section{Квазидвумерная геометрия}

Для объяснения наблюдаемых зависимостей параметров люминесценции растворов от наличия в них УНТ были предложены несколько вариантов электродинамической модели концентрационной активации-тушения люминесценции MEH-PPV углеродными нанотрубками. В простейшем случае разбавленных по УНТ растворов система представлялась отдельными, не взаимодействующими друг с другом трехслойными наноцилиндрами большой длины с заданными диэлектрическими проницаемостями $\varepsilon_{j}(j=1,2,3)$ каждого из слоев, и использовалось приближение квазистатического поля. В случае с окруженной полимерной цепью нанотрубкой задача редуцируется к двумерной, если все диполи звеньев цепи, находящиеся на линии, параллельной оси УНТ, могут рассматриваться как эквивалентные. Тогда можно говорить о двумерном диполе, создающем поле $E_{2}(r, \varphi)$ в кольце-сечении самой трубки и $E_{3}(r, \varphi)-$ в опушечном слое. Это возможно, если экситоны MEH-PPV сильно делокализованы. При таком подходе рассматривается поляризуемость $1 \alpha(\omega)$ единицы длины цилиндра. Для частотной зависимости скорости спонтанного излучения системы „макроцепь-нанотрубка“ использовалось выражение [11]

$$
w_{s p}(\omega \mid \mathbf{r})=\frac{1}{4} \frac{\omega^{3}}{\hbar c^{3}}\left|[\overleftrightarrow{\mathbf{I}}+\overleftrightarrow{\mathbf{G}}(\mathbf{r}) \alpha(\omega)] \mathbf{p}_{0}\right|^{2}
$$

Отметим, что в (1) в отличие от случая $3 d$-системы используется двумерная диадическая функция Грина 
$\overleftrightarrow{\mathbf{G}}(\mathbf{r})=r^{-2}\left[2 r^{-2} \mathbf{r} \otimes \mathbf{r}-\overleftrightarrow{\mathbf{I}}\right]$, где $\overleftrightarrow{\mathbf{I}}-$ тензорная единица, $r$ - расстояние от оси трубки до точки локализации экситона на макроцепи, $\mathbf{p}_{0}$ - электронный дипольный момент отдельного звена цепи.

\section{УНТ-тушение возбуждений}

Конкурирующим процессом для излучательного экситонного перехода является безызлучательный перенос энергии от полимерной цепи к нанотрубке, т. е.

гибель экситона с рождением плазмона в УНТ. Для скорости $U(\omega \mid \mathbf{r})$ соответствующего элементарного акта такого процесса можно записать [11] $(\alpha(\omega)$ - поляризуемость единицы длины нанотрубки)

$$
U(\omega \mid \mathbf{r})=(2 \hbar)^{-1} \operatorname{Im}\left[\mathbf{p}_{0} \overleftrightarrow{\mathbf{G}}(\mathbf{r}) \alpha(\omega) \overleftrightarrow{\mathbf{G}}(\mathbf{r}) \mathbf{p}_{0}\right]
$$

Обе скорости (1) и (2) имеют радиальную зависимость степенного характера вследствие наличия таковой у тензора $\mathbf{G}(\mathbf{r}) \sim r^{-2}$. Наивысший показатель степени и в (1), и в (2) равен -4. Однако наличие интерференционного слагаемого $w_{s p}^{\text {int }}(\omega \mid \mathbf{r}) \sim 2 \operatorname{Re} \alpha(\omega) \mathbf{p}_{0} \overleftrightarrow{\mathbf{G}}(\mathbf{r}) \mathbf{p}_{0}$ в (1) обусловливает степенной закон с показателем -2: $w_{s p}^{\text {int }}(r) \sim r^{-4}$, тогда как радиальная зависимость скорости (2) носит характер . Это различие скоростей радиационного и безызлучательного переходов в степенных зависимостях от расстояния между частями нанокомпозита, по всей видимости, и отвечает за доминирование тушения над излучением [12] при сближении нанотрубки с излучающим звеном цепи. При наличии большого числа нанотрубок в растворе среднее расстояние между центром свечения и стоком уменьшается, что приводит к подавлению режима плазмонной активации люминесценции и возрастанию эффективности канала тушения.

Скорость безызлучательного переноса энергии электронного возбуждения (БПЭЭВ) от экситонактивированной макроопушки к УНТ вместо (2) может быть определена выражением, не использующим поляризуемость $\alpha(\omega)$ и приближение однородного поля, а содержащим диэлектрическую проницаемость $\varepsilon_{2}(\omega)$ графенового слоя нанотрубки толщиной $\delta$ :

$$
U(\omega)=(2 \hbar)^{-1} \int_{R-\delta}^{R} \int_{2 \pi} \operatorname{Im} \varepsilon_{2}(\omega)\left|E_{2}(r, \varphi)\right|^{2} r d r d \varphi .
$$

\section{Моделирование зависимости интенсивности свечения от концентрации нанотрубок}

Для иллюстрации этой зависимости рассматривалась двумерная периодическая наноструктура, являющаяся сечением решетки из параллельных нанотрубок, пространство между которыми заполнено макроцепями MEH-PPV. Ячейка с одной нанотрубкой в центре формировалась по методу Вигнера-Зейца, тогда ее радиус составлял половину расстояния между соседними нанотрубками. С ростом концентрации УНТ этот радиус уменьшается вплоть до предельного значения $R$, a вместе с ним падает и число звеньев макроцепей MEH-PPV, зажатых между нанотрубками. При этом уменьшается и доля звеньев полимера относительно удаленных от поверхности УНТ, а значит, и число наименее подверженных тушению экситонов, локализованных на таких звеньях, что соответствует наблюдаемым в эксперименте концентрационным зависимостям. Рост числа нанотрубок в системе учитывается через уменьшение размеров ячейки эффективной двумерной решетки, образованной параллельно размещенными нанотрубками.

\section{Локализованный экситон. $3 d$-геометрия}

При локализации экситона на макроцепи MEH-PPV следует говорить о точечном дипольном источнике. Скорость БПЭЭВ от донорного центра с дипольным моментом $\mathbf{p}_{0}$ к нанопроволоке радиуса $R$ может быть записана в виде [13]

$$
U_{\alpha}(\omega)=\frac{1}{2 \pi \hbar} \operatorname{Im} \varepsilon_{2}(\omega) \int \mathbf{E}_{\alpha} \mathbf{E}_{\alpha}^{*} d V
$$

Более удобно анализировать асимптотическую форму (4). Так, при $r-R=\Delta \ll R$ скорость переноса (4) принимает вид $U_{\alpha} \sim \Delta^{-3}$, где $\alpha=x, y, z-$ одна из трех взаимно ортогональных ориентаций экситонного диполя. Действительно, из (4) следует [13]

$$
U_{\alpha}(\omega)=c_{\alpha} \frac{p_{0}^{2}}{\hbar \varepsilon_{\mathrm{eff}}^{2}} \frac{\varepsilon_{1}}{\Delta^{3}} \operatorname{Im}\left[\frac{\varepsilon_{2}(\omega)-\varepsilon_{1}}{\varepsilon_{2}(\omega)+\varepsilon_{1}}\right],
$$

где $c_{\alpha}$ представляет собой ориентационный коэффициент; $c_{x}=1 / 2, c_{y}=c_{z}=1 / 4 ; \varepsilon_{\text {eff }}=\left(2 \varepsilon_{1}+\varepsilon_{2}\right) / 3$.

В другом важном предельном случае $r \gg R$ из (4) следует выражение

$$
\begin{aligned}
U_{\alpha}(\omega)= & \frac{R^{2}}{\hbar r^{5}} \frac{p_{0}^{2}}{\varepsilon_{\mathrm{eff}}^{2}} \\
& \times \frac{3 \pi}{16}\left[a_{\alpha}+\left|\frac{\varepsilon_{3}}{\varepsilon_{2}(\omega)+\varepsilon_{3}}\right|^{2} b_{\alpha}\right] \operatorname{Im} \varepsilon_{2}(\omega),
\end{aligned}
$$

где коэффициент $a_{\alpha}$ равен 15/16, 0 и 9/16 для $x$-, $y$ - и $z$-поляризаций соответственно. Соответствующие величины коэффициентов $b_{\alpha}: 41 / 4,4$ и 15/4. Менее резкая дистанционная зависимость в (5) и (6) по сравнению с $U(r) \sim r^{-6}$ в формуле Ферстера для молекулярной донорно-акцепторной пары обусловлена одномерной геометрией нанотрубки-акцептора в переносе энергии [14].

В [15] показано, что если молекула размещена непосредственно вблизи поверхности наноцилиндра, т.е. $r \rightarrow R$, то относительная скорость распада возбуждения по безызлучательному каналу для $r, \varepsilon$ и $z$-ориентаций диполя может быть представлена в виде

$$
\left(\frac{w}{w_{0}}\right)_{r}^{\text {nonrad }}=\frac{3 \lambda^{3}}{2 \pi^{3}(r-R)^{3}} \operatorname{Im}\left[\frac{\varepsilon_{2}(\omega)-\varepsilon_{1}}{\varepsilon_{2}(\omega)+\varepsilon_{1}}\right],
$$




$$
\begin{aligned}
\left(\frac{w}{w_{0}}\right)_{\varphi}^{\text {nonrad }} & =\left(\frac{w}{w_{0}}\right)_{z}^{\text {nonrad }} \\
& =\frac{3 \lambda^{3}}{4 \pi^{3}(r-R)^{3}} \operatorname{Im}\left[\frac{\varepsilon_{2}(\omega)-\varepsilon_{1}}{\varepsilon_{2}(\omega)+\varepsilon_{1}}\right] .
\end{aligned}
$$

Авторы [15] отмечают, что выражения (7) подобны тем аналогам, которые обычно получаются для отраженного поля методом диполей-изображений в случае плоской диэлектрической поверхности. В свою очередь заметим, что $r-R=\Delta$, и они полностью совпадают c (5) с точностью до множителей, которые к тому же могут быть отождествлены или соответствующим образом нормированы ( $\lambda$ - длина световой волны в среде). Кроме того, в [11] на примере кремния с $\operatorname{Im} \varepsilon \sim 10^{-9}$ показано, что безызлучательные потери очень малы для всех разумных расстояний между молекулой и поверхностью. Однако в том случае, когда молекула размещена непосредственно на поверхности, эти потери могут существенно возрасти.

В более детализированном варианте математической модели учитываются неоднородность поляризующего поля в нанотрубке и радиальное распределение плотности звеньев адсорбированной макроцепи. В таком подходе удельная поляризуемость композита не рассматривается, а дипольный момент единицы длины нанотрубки, индуцированный полем экситонного диполя, вычисляется через вектор поляризации $\mathbf{P}(\mathbf{r})$ УНТ. Сoгласно статистической теории распределения плотности звеньев полимерной цепи на поверхностях адсорбентов [16], плотность звеньев макроцепи $n(\mathbf{n})$ определяется квадратом функции $\psi(\mathbf{r})$ :

$$
n(\mathbf{r})=\text { const } \psi^{2}(\mathbf{r}) \text {. }
$$

В работе [17] была определена радиальная зависимость концентрации звеньев на поверхности цилиндрической наночастицы с $\delta$-функциональной ямой, моделирующей притяжение звеньев полимерной молекулы к поверхности радиуса $r_{0}>R$, охватывающей нанотрубку:

$$
\begin{cases}\psi_{I}=A\left(I_{0}(q r)-K_{0}(q r) \frac{I_{0}(q R)}{K_{0}(q R)}\right), & R<r<r_{0} \\ \psi_{I I}=A K_{0}(q r)\left(\frac{I_{0}\left(q r_{0}\right)}{K_{0}\left(q r_{0}\right)}-\frac{I_{0}(q R)}{K_{0}(q R)}\right), & r_{0}<r<\infty\end{cases}
$$

где $I_{0}(x)$ и $K_{0}(x)$ - функции Бесселя мнимого аргумента нулевого порядка первого и второго рода, $A=$ const, а параметр $q$ находится из уравнения

$$
K_{0}\left(q r_{0}\right) I_{0}\left(q r_{0}\right)=\frac{a^{2} k_{B} T}{6 \alpha r_{0}}+K_{0}^{2}\left(q r_{0}\right) \frac{I_{0}(q R)}{K_{0}(q R)},
$$

где $a$ - размер мономера, $\alpha$ - параметр глубины потенциальной ямы, $k_{B} T-$ тепловая энергия. Тогда вектор поляризации $\mathbf{P}(\mathbf{r})$ макроцепной опушки с экситонным диполем $\mathbf{p}_{0}$ может быть записан в виде $\mathbf{P}(\mathbf{r}) \sim \mathbf{p}_{0} \psi^{2}(r)$. Индуцированный дипольный момент $\mathbf{p}_{N T}$ нанотрубки определяется интегралом от вектора поляризации в ее слое:

$$
\mathbf{p}_{N T}=\frac{1}{4 \pi} \int_{R-\delta}^{R} \int_{2 \pi}\left[\varepsilon_{2}(\omega)-\varepsilon_{3}(\omega)\right] E_{2}(\mathbf{r}) r d r d \varphi .
$$

Напряженность поля $E_{2}(r, \varphi)=-\nabla u_{2}(r, \varphi)$ в графеновом слое нанотрубки находится из решения уравнения Лапласа $\nabla^{2} u_{2}(r, \varphi)=0$ для скалярного потенциала $u_{2}(r, \varphi)$. Эффективный дипольный момент перехода системы можно представить в виде

$$
\begin{aligned}
\mathbf{p}_{\mathrm{eff}} & =\mathbf{p}_{N T}+\int_{R}^{\infty} \int_{2 \pi} \mathbf{P}(\mathbf{r}) r d r d \varphi \\
& =\mathbf{p}_{N T}+\mathbf{p}_{0} \int_{R}^{\infty} \int_{2 \pi} \psi^{2}(r) r d r d \varphi .
\end{aligned}
$$

Объемная плотность электрического заряда в опушке $-\operatorname{div} \mathbf{P}(\mathbf{r})=\rho(r, \varphi)$, откуда

$$
\rho_{\alpha}(r, \varphi)=-\left(\mathbf{p}_{0} \mathbf{n}\right)_{\alpha} \frac{d}{d r} \psi^{2}(r) .
$$

Тогда потенциал поля $u_{3}(r, \varphi)$ находим из решения уравнения Пуассона

$$
\nabla^{2} u_{3}(r, \varphi)=-4 \pi \rho_{\alpha}(r, \varphi) .
$$

На внешней поверхности нанотрубки выполняются равенства

$$
\begin{gathered}
u_{2}(R, \varphi)=u_{3}(R, \varphi), \\
\left.\varepsilon_{2}(\omega) \frac{d}{d r} u_{2}(r, \varphi)\right|_{R}=\left.\varepsilon_{3} \frac{d}{d r} u_{3}(r, \varphi)\right|_{R} .
\end{gathered}
$$

В случае аппроксимации полимерной опушки однородным слоем толщиной $\Delta=R_{3}-R_{2}$ для плотности $\psi^{2}(\mathbf{r})$ можем записать $\psi^{2}(\mathbf{r})=1 /\left[\pi\left(R_{3}^{2}-R_{2}^{2}\right)\right]$ и тогда

$$
2 \pi \mathbf{p}_{0} \int_{R_{2}}^{R_{3}} \psi^{2}(r) r d r d \varphi=\mathbf{p}_{0}, \quad \mathbf{p}_{\mathrm{eff}}=\mathbf{p}_{N T}+\mathbf{p}_{0} .
$$

В случае точечного молекулярного диполя и однородного наноцилиндра радиуса $R$ [15] наведенный дипольный момент на единицу его длины в случае радиальной ориентации дипольного момента

$$
\delta p_{r}=p_{0} \frac{\varepsilon_{2}(\omega)-\varepsilon_{1}}{\varepsilon_{2}(\omega)+\varepsilon_{1}} \frac{R^{2}}{r_{0}^{2}},
$$

где $r_{0}>R$ - расстояние от оси цилиндра до диполя $p_{0}$. В случае трансверсальной ориентации дипольного момента

$$
\delta p_{\varphi}=-p_{0} \frac{\varepsilon_{2}(\omega)-\varepsilon_{1}}{\varepsilon_{2}(\omega)+\varepsilon_{1}} \frac{R^{2}}{r_{0}^{2}} .
$$


Относительная скорость радиационного распада молекулы вблизи сплошного наноцилиндра для различных поляризаций диполя $p_{0}[15]$

$$
\begin{gathered}
\left(\frac{w}{w_{0}}\right)_{r}=\left|1+\frac{\varepsilon_{2}(\omega)-\varepsilon_{1}}{\varepsilon_{2}(\omega)+\varepsilon_{1}} \frac{R^{2}}{r_{0}^{2}}\right|^{2}, \\
\left(\frac{w}{w_{0}}\right)_{\varphi}=\left|1-\frac{\varepsilon_{2}(\omega)-\varepsilon_{1}}{\varepsilon_{2}(\omega)+\varepsilon_{1}} \frac{R^{2}}{r_{0}^{2}}\right|^{2},\left(\frac{w}{w_{0}}\right)_{z}=1 .
\end{gathered}
$$

В случае идеально проводящего цилиндра выражения для плазмон-инициированных скоростей распада молекулы приведены в [18].

С учетом диссипации энергии в результате ее безызлучательного переноса на УНТ для скорости $N_{\omega}$ спонтанного излучения фотонов с частотой $\omega$ можем записать

$$
N_{\omega}=\frac{1}{2 \pi}\left[\frac{w_{s p}(\omega) \Gamma_{\text {tot }}^{2}(\omega)}{\left(\omega-\omega_{i f}\right)^{2}+\Gamma_{\text {tot }}^{2}(\omega)}\right] \eta(\omega),
$$

где $\omega_{i f}$ - частота экситонного перехода, а квантовый выход люминесценции $\eta(\omega)$ на частоте определен как

$$
\eta(\omega)=\frac{w_{s p}(\omega)}{\Gamma_{\text {tot }}(\omega)}, \quad \Gamma_{\text {tot }}(\omega)=w_{s p}(\omega)+U(\omega)+K,
$$

где $K$ - скорость мономолекулярного безызлучательного распада электронного возбуждения, а скорость $w_{s p}(\omega)$ спонтанного испускания в (16) и (17) определена выражением

$$
w_{s p}(\omega)=\frac{1}{4} \frac{\omega^{3}}{\hbar c^{3}}\left|\mathbf{p}_{\mathrm{eff}}(\omega)\right|^{2}
$$

где $\mathbf{p}_{\mathrm{eff}}(\omega)=\mathbf{p}_{0}(\omega)+\delta \mathbf{p}(\omega)$, с $\delta \mathbf{p}(\omega)$ из (13) или (14).

$\mathrm{B}$ результате для скорости испускания фотонов с частотой $\omega$ получаем

$$
N_{\omega}=\frac{1}{2 \pi}\left[\frac{w_{s p}^{2}(\omega) \Gamma_{\mathrm{tot}}(\omega)}{\left(\omega-\omega_{i f}\right)^{2}+\Gamma_{\mathrm{tot}}^{2}(\omega)}\right] .
$$

\section{FDTD-моделирование характеристик поля вблизи УНТ с опушкой МЕН-PPV и в дальней зоне}

При проведении более строгих расчетов характеристик поля углеродные нанотрубки аппроксимировались однородными полыми цилиндрами из материала, обладающего оптическими свойствами графена (рекомендованными для моделирования свойств УНТ в нанофотонике). В случаях, когда длина нанотрубки превышала линейный размер области моделирования, рассматривались УНТ без окончаний, в других случаях эти окончания аппроксимировались полусферами. Моделирование характеристик электромагнитного поля производилось на основе уравнений Максвелла, для численного решения которых использовался метод конечных разностей во временной области с участками без свободных зарядов (метод FDTD с базовым алгоритмом прямоугольной сетки Йи).

Адсорбированная на УНТ полимерная цепь аппроксимировалась коаксиальным с нанотрубкой цилиндрическим слоем. В результате композитная модельная система представляла собой полый двуслойный цилиндр с различными диэлектрическими проницаемостями каждого из слоев. Использовалась частотная зависимость комплексной диэлектрической проницаемости $\varepsilon(\omega)$ MEHPPV из [19]. Согласно [19], максимум мнимой части $\operatorname{Im} \varepsilon(\omega)$ располагался в области $500 \mathrm{~nm}$ - в соответствии с известным спектром оптического поглощения MEH-PPV [20]. Максимум спектра фотолюминесценции MEH-PPV приходится на $560 \mathrm{~nm}$. Реальная часть диэлектрической проницаемости толуола принималась равной 2.28 , а мнимая часть - нулю.

Важно отметить, что на частоте $500 \mathrm{THz}$ (что соответствует длине волны $600 \mathrm{~nm}$ ) диэлектрическая проницаемость графена отрицательна, поэтому вдоль границы раздела сред графен-MEH-PPV может распространяться волна в виде поверхностного плазмон-поляритона. Другими словами, нанотрубка может выступать в роли своеобразного волновода и влиять на перераспределение энергии в исследуемой системе. Заметим, что это предположение находит подтверждение в работе [21], в которой наблюдалось распространение волн возбуждения (экситонов по терминологии авторов) вдоль углеродных нанотрубок.

Для ограничения размера сетки и устранения эффекта отражения волн в исследуемую область, искажающего картину, в методе FDTD вводятся особые поглощающие граничные условия или идеально согласованные слои, моделирующие уход электромагнитной волны на бесконечность.

В ходе FDTD-расчета задавались расчетная область, разрешение сетки и граничные условия. Внутри расчетной области, заполненной растворителем (толуол), помещались УНТ с дипольным источником электромагнитных волн необходимого спектрального состава. Генерируемая волна рассеивается на нанотрубках и их покрытиях и покидает область моделирования. С помощью преобразования Фурье записанные значения характеристик поля переводятся в частотное представление. В результате соответствующей обработки (например, интегрирования потока энергии поля через какуюлибо поверхность) можно получить выходные оптические характеристики рассматриваемой наноструктуры. Используя метод преобразования ближнего поля в дальнее (Near to Far Transformation), получаем значения полей за пределами расчетной области на основании эволюции поля внутри нее. Метод FDTD позволяет получить широкополосный по спектру результат за один расчет. Для наглядности создавались анимированные изображения распространяемой волны в моделируемом объеме. Величина шага дискретизации в пространстве была значительно меньше исследуемых длин волн и типичных размеров исследуемой структуры. 


\section{Параметры области моделирования}

Моделирование проводилось в трехмерном пространстве, область моделирования имела форму куба с ребром $2 \mu \mathrm{m}$, длительность моделирования - $20 \mathrm{fs}$, минимальный шаг сетки $-0.1 \mathrm{~nm}$. Тип источника излучения - электрический диполь, частота излучения $500 \mathrm{THz}$, что соответствует максимуму спектра фотолюминесценции MEH-PPV (длина волны $600 \mathrm{~nm}$ [20]). Шесть внешних граней области моделирования: top (верхняя, $z>0$ ), down (нижняя, $z<0$ ), left (левая, $x<0$ ), right (правая, $x>0$ ), front (передняя, $y<0$ ) и back (задняя, $y>0$ ). Центр исследуемой области располагался в начале координат. В совокупности эти грани-площадки составляли замкнутую поверхность, в результате чего учитывается все поле, достигшее дальней зоны. Для удобства анализа данных рисовалась гистограмма, отражающая долю энергии, прошедшую через каждую грань. Цвет в получаемом двумерном изображении характеризовал интенсивность электромагнитного поля, достигшего поверхности. Таким образом, появляется возможность провести анализ перераспределения энергии дипольного источника излучения между шестью направлениями в заданной геометрии системы.

Какая-то часть цепей MEH-PPV не адсорбируются на поверхности углеродных нанотрубок, а остается свободно взвешенной в растворе. Для учета вклада этой части полимера вводилась эффективная диэлектрическая проницаемость $\varepsilon_{\text {eff }}(\omega)$ MEH-PPV-содержащего раствора толуола как

$$
\varepsilon_{\mathrm{eff}}(\omega)=\eta \varepsilon_{3}(\omega)+(1-\eta) \varepsilon_{1}(\omega),
$$

где $0<\eta<1-$ доля содержания MEH-PPV в растворе толуола.

Значения параметра $\eta$ для раствора, использованного в эксперименте, можно оценить как 0.1-0.2. В чистом толуоле электромагнитное поле будет распространяться без поглощения на интересующей нас частоте, что может помешать обнаружению различных особенностей формирования поля. Введенная эффективная диэлектрическая проницаемость $\varepsilon_{\mathrm{eff}}(\omega)$ должна на качественном уровне приблизить предложенную модель к реальной физической картине.

Для проведения вычислительного эксперимента в области моделирования размещалась углеродная нанотрубка длиной $1.6 \mu \mathrm{m}$. Размер области моделирования составлял: $0.6 \times 2.0 \times 0.6 \mu \mathrm{m}$. Наибольший линейный размер области моделирования соответствовал направлению оси нанотрубки.

Растворитель - толуол. Толщина графенового слоя составляла $1 \mathrm{~nm}$, внешний радиус трубки $-5 \mathrm{~nm}$. Толщина макромолекулярной опушки составляла $5 \mathrm{~nm}$, внешний радиус опушечного слоя MEH-PPV $-10 \mathrm{~nm}$.

Центр нанотрубки располагался в начале координат, а источник излучения был смещен на $10 \mathrm{~nm}$ в вертикальном направлении $(z=0.01 \mu \mathrm{m})$. Монитор визуального
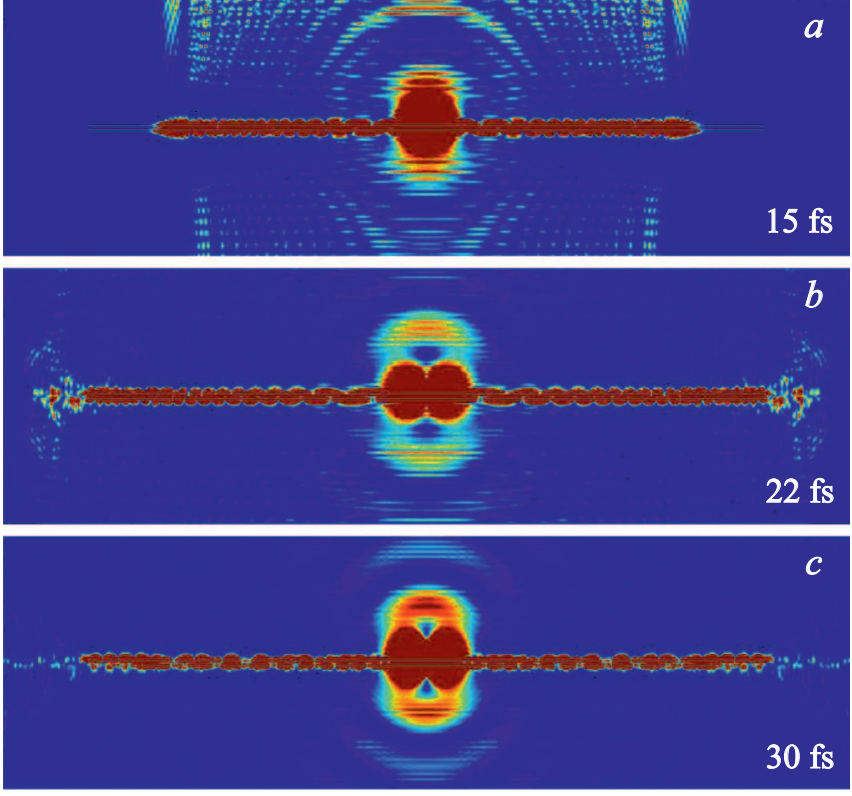

Рис. 3. Картина распространения электромагнитной волны вдоль нанотрубки для трех моментов времени: $a-15, b-22$, $c-30 \mathrm{fs}$. Вектор дипольного момента источника ориентирован вдоль оси нанотрубки.

представления данных размещался в одном из сечений нанотрубки и проходил через ее ось.

\section{Влияние углеродных нанотрубок на пространственное распределение энергии излучения дипольного источника}

Наблюдаемая картина изменялась в зависимости от ориентации дипольного момента излучателя. В случае, когда вектор дипольного момента был ориентирован вдоль оси нанотрубки, эффект распространения электромагнитного поля вдоль нанотрубки наблюдался наиболее отчетливо. Картина распространения электромагнитной волны вдоль поверхности нанотрубки изображена на рис. 3.

В результатах численного эксперимента можно условно выделить три этапа.

а. Энергия дипольного источника излучения частично излучается в пространство, а частично передается нанотрубке, которая выступает в качестве цилиндрического нановолновода, вдоль которого распространяются плазмоны. Их интенсивность очень слабо спадает с пройденным расстоянием по сравнению с интенсивностью поля в свободном пространстве.

б. Электромагнитная волна достигает конца нанотрубки и разделяется на две части: первая продолжает распространяться в прежнем направлении, что выражается в наличии отчетливо заметного веерного шлейфа на обоих концах нанотрубки (рис. $3, b, c)$. Вторая часть отражается от концов трубки и продолжает движение в обратном направлении. 
в. В результате сложения первичной и отраженной волн внутри нанотрубки формируются биения, при этом достаточно интенсивные „веерные“ волны продолжают излучаться из обоих концов нанотрубки.

Таким образом, в течение трети всего времени моделирования, от 20 до $30 \mathrm{fs}$, начиная с этапа б, с обоих концов нанотрубки происходит испускание „фонтанных“ электромагнитных волн достаточно большой интенсивности в свободное пространство, что подтверждает гипотезу о волноводных свойствах одностенных углеродных нанотрубок. Если же дипольный момент источника излучения перпендикулярен оси нанотрубки, то подобные процессы также имеют место, однако их интенсивность заметно ослабевает. Однако и в этом случае интенсивность электромагнитной волны, распространяющейся вдоль нанотрубки, значительно выше интенсивности волн, излучаемых в пространство с характерной индикатрисой, присущей дипольному источнику. Как и в случае соосной ориентации дипольного момента при скрещенной конфигурации диполя, также отчетливо наблюдается разделение волны, достигшей конца нанотрубки на „фонтанный шлейф“ и отраженную часть. „Шлейф“ на этапе в в этой геометрии имеет меньшую интенсивность, чем при соосной ориентации диполя в предыдущем примере.

Были проведены дополнительные эксперименты с нанотрубкой без макромолекулярной опушки, а также с цилиндрическим слоем MEH-PPV, но уже без нанотрубки в идентичных условиях. Иными словами, были исследованы волноводно-антенные характеристики фрагментарных наноструктур. Ориентация вектора дипольного момента во всех экспериментах оставалась неизменной.

Размер области моделирования в расчетах был увеличен до значений $0.6 \times 3.6 \times 0.6 \mu \mathrm{m}$. Расстояние от концов нанотрубки до границ области моделирования примерно составляло $1 \mu \mathrm{m}$, что в условиях проводимого численного эксперимента можно было считать дальней зоной. На границах, перпендикулярных оси нанотрубки, были установлены мониторы, интегрирующие энергию поля, достигшего дальней зоны. Расчеты показали, что композитная система из углеродной нанотрубки с адсорбированным слоем MEH-PPV обладает наиболее выраженными антенными свойствами энергопередачи в определенных направлениях (100\%) по сравнению с другими наноструктурами схожей геометрии: УНТ без слоя MЕН-PРV (18\%) и слой МЕН-PРV без УНТ (9\%).

В другом эксперименте углеродную нанотрубку длиной $1.6 \mu \mathrm{m}$ располагали в объеме моделирования размером $2.0 \times 3.6 \times 2.0 \mu \mathrm{m}$. Такой размер области моделирования был выбран исходя из условия размещения всех шести мониторов в дальней зоне в рамках технических ограничений, накладываемых на объем памяти в проводимой симуляции. В этом случае производилось интегрирование полной энергии поля, достигшего замкнутой поверхности, образованной шестью гранями в дальней зоне, а не через две грани на оси УНТ, как это было в первом эксперименте.
Эксперименты показали, что наибольший вклад в перераспределение энергии источника излучения нанотрубка оказывает в случае, когда вектор дипольного момента расположен параллельно ее оси. В этих экспериментах был проинтегрирован поток энергии поля, достигший дальней зоны от источника излучения вблизи углеродной нанотрубки со слоем MEH-PРV. В качестве контрольной системы сравнения выступал полый цилиндрический слой MEH-PPV без углеродной нанотрубки. Эксперименты проводились как для чистого раствора толуола, так и для коллоида, состоящего из 90\% толуола с 10\% взвешенных в объеме примесей MEH-PPV. Результаты этого эксперимента отражены на гистограмме рис. 4.

В эксперименте с коллоидным раствором толуола с 10\% примесью MEH-PPV наблюдалось увеличение потока энергии поля, достигшего дальней зоны, относительно случая, когда нанотрубка отсутствовала или присутствовала только оболочка из MEH-PPV без УНТ. Это увеличение составило около $14 \%$ на всех шести мониторах, что свидетельствует о возможности влияния углеродных нанотрубок на увеличение интенсивности собственной люминесценции звеньев полимерной цепи MEH-PРV. При этом рост потока энергии вдоль оси нанотрубки в дальнюю зону составил $20 \%$.

Таким образом, углеродные нанотрубки могут выступать в роли своеобразных антенн, избирательно увеличивающих скорость спонтанного излучения в определенных направлениях. Теоретические построения, объясняющие изменение скорости спонтанного излучения атомов вблизи нанотел цилиндрической геометрии, представлены в [22], эти результаты созвучны с предположениями, изложенные выше. „С физической точки зрения этот эффект обусловлен тем, что радиальный диполь возбуждает в цилиндре слабо спадающую с расстоянием волну тока, которая является источником мощного излучения" - заключают авторы [22]. То есть из формулы (15) следует, что максимальный эффект усиления люминесценции должен наблюдаться при радиальной ориентации диполя, в то время как вычислительный DFTD-эксперимент выявил соосную ориентацию дипольного момента в качестве оптимальной для эффекта. Возможно, это связано с тем, что полый проводящий цилиндр, каковым является УНТ, обладает иными плазмонными свойствами, что отмечалось и в [23], по сравнению со сплошным нанопроводом, для которого получено выражение (15).

\section{Безызлучательный перенос энергии между двумя УНТ}

В следующем эксперименте в области моделирования поля было размещено уже две нанотрубки для определения степени их взаимного влияния, выражающегося в особенностях формирования ближнего поля. Вблизи одной из нанотрубок, как и в предыдущих экспериментах, размещался дипольный источник излучения. Рядом с ней 


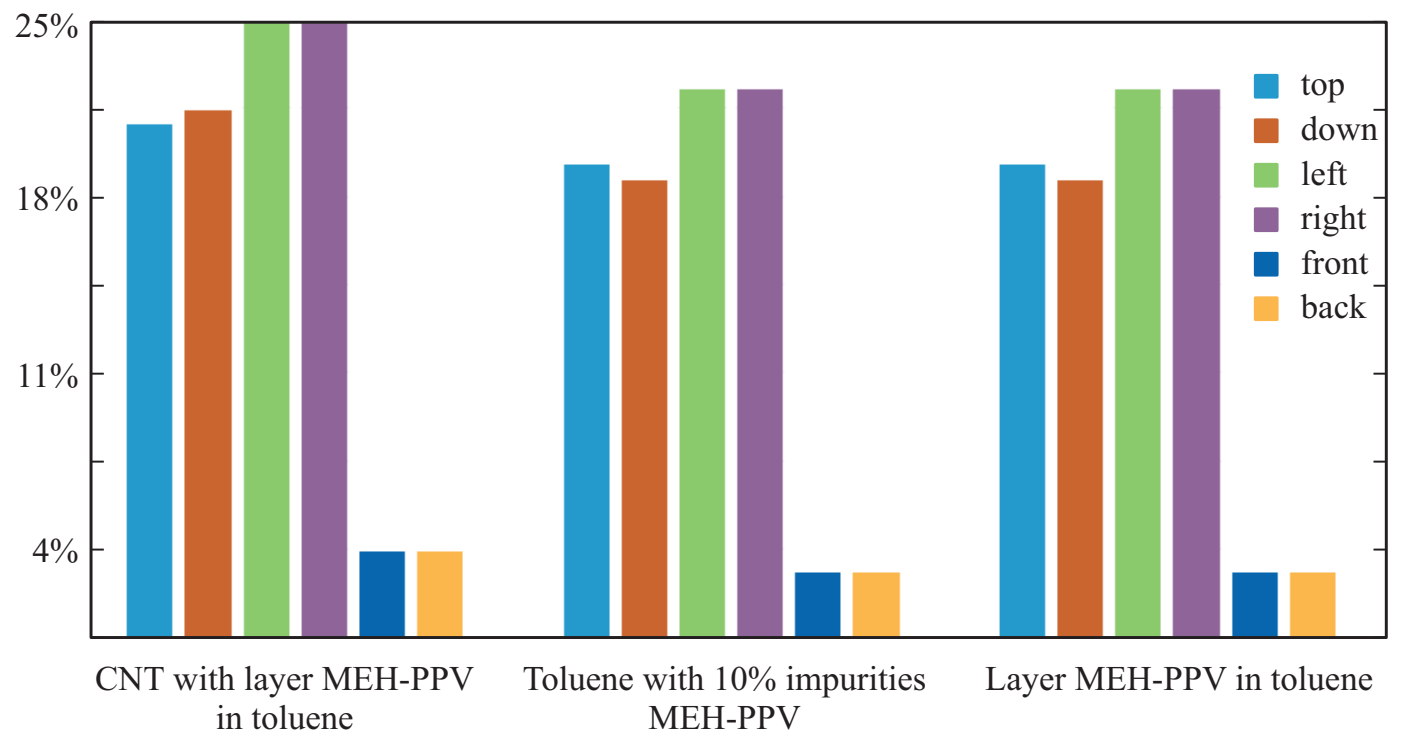

Pис. 4. Гистограмма распределения энергии поля в дальней зоне по шести направлениям в трех экспериментах: УНT со слоем MEH-PPV (левая группа), коллоидный раствор без УНТ и без слоя МЕН-PРV (средняя группа) и тубуленный слой МЕН-PРV без УНТ (правая группа). В качестве растворителя использовался толуол с $10 \%$ примесью MEH-PPV $(\eta=0.1)$.

параллельно, но на значительном удалении от источника размещалась вторая нанотрубка. Предполагалось, что электромагнитная волна, распространяющаяся в первой нанотрубке, может индуцировать аналогичные процессы и во второй нанотрубке.

В проведенных экспериментах расстояние между осями нанотрубок составляло от 20 до $40 \mathrm{~nm}$, что в масштабе длины волны излучения может считаться близким расположением. Во всех исследованных случаях оказалось, что часть энергии электромагнитной волны, распространявшейся в первой нанотрубке, передавалась ко второй, в результате чего наблюдалось появление схожей волны, распространяющейся уже вдоль второй нанотрубки (рис. 5). При распараллеливании нанотрубок наблюдаемый эффект межтубуленного экспорта волны сильно ослабевает.

Таким образом, приходим к выводу, что и трубкасаттелит может выступать в роли своеобразного волновода. То есть помимо наблюдавшейся в эксперименте безызлучательной передачи энергии между двумя нанотрубками [24] в акцепторной подсистеме эта энергия принимает организованную форму в виде поверхностной плазмон-поляритонной волны. Схожий результат наблюдался и в экспериментальной работе [21], в которой приведены снимки, сделанные при помощи оптической микроскопии высокого разрешения, на которых авторам удалось визуализировать безызлучательный перенос энергии между двумя углеродными нанотрубками.

Таким образом, в ходе проведенных вычислительных экспериментов было установлено, что углеродные нанотрубки со слоем MEH-PPV обладают направленными антенными свойствами, выступая в роли своеобразного волновода. Часть энергии излучения, достигшей дальней зоны в направлении оси нанотрубки, на порядок выше, чем в случае ее отсутствия. Заслуживает особого внимания ряд эффектов, наблюдавшихся в ходе численных экспериментов: хорошо заметный „шлейф“ электромагнитной волны, исходящий из обоих концов нанотрубки, а также стадия биений, характеризующая нанотрубку как волновод. Подтверждена наблюдавшаяся ранее в ряде работ [21,24] безызлучательная передача энергии между близкорасположенными нанотрубками и обнаружено появление плазмонной волны в нанотрубкеакцепторе. Суммарный поток энергии поля, достигшего дальней зоны через замкнутую поверхность, подтверждает экспериментально наблюдаемое увеличение интегральной люминесценции раствора, содержащего МЕНPPV с УНТ при определенной концентрации последних.

\section{Молекулярно-динамическое моделирование структуры макромолекулы MEH-PPV вблизи одной и двух параллельных УНТ}

Кроме реализации электродинамической модели в работе выполнено молекулярно-динамическое моделирование конфигураций адсорбированной цепи MEH-PPV как на отдельной углеродной нанотрубке в различных растворителях, так и на двух параллельно расположенных нанотрубках с вариацией расстояния между ними. В результате было установлено, что полимерная цепь адсорбируется на поверхности углеродной нанотрубки.

Молекулярно-динамическое (МД) моделирование адсорбции макромолекулярной цепи МЕН-PРV, состоящей из 500 звеньев, производилось на поверхности одностенной углеродной нанотрубки в воде и толуоле, а 

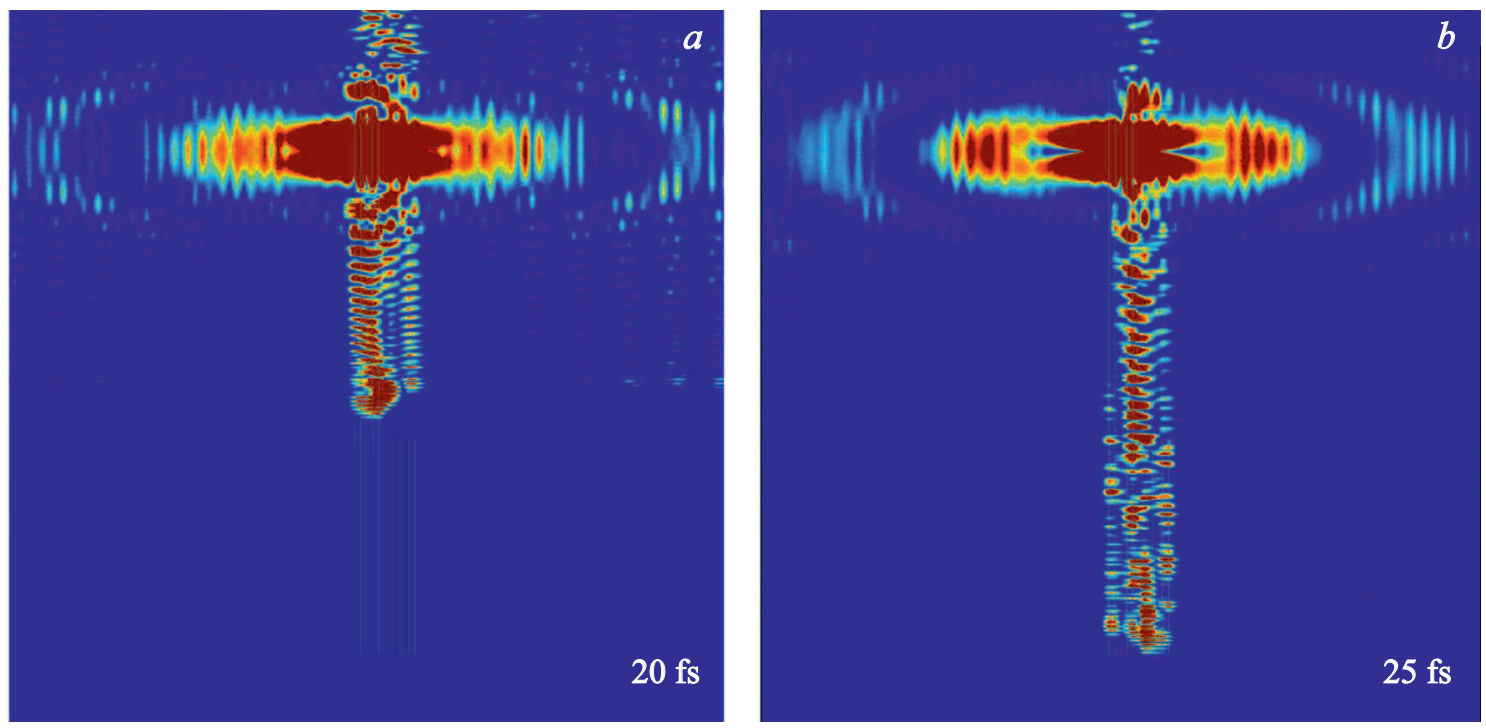

Рис. 5. Возникновение электромагнитных волн, распространяющихся вдоль структуры, состоящей из двух параллельных УНТ. $a-20 \mathrm{fs}$, начальный этап появления волны в одной нанотрубке, ближайшей к точечному дипольному источнику; $b-25 \mathrm{fs}$, последующий этап появления волны-спутника во второй нанотрубке.
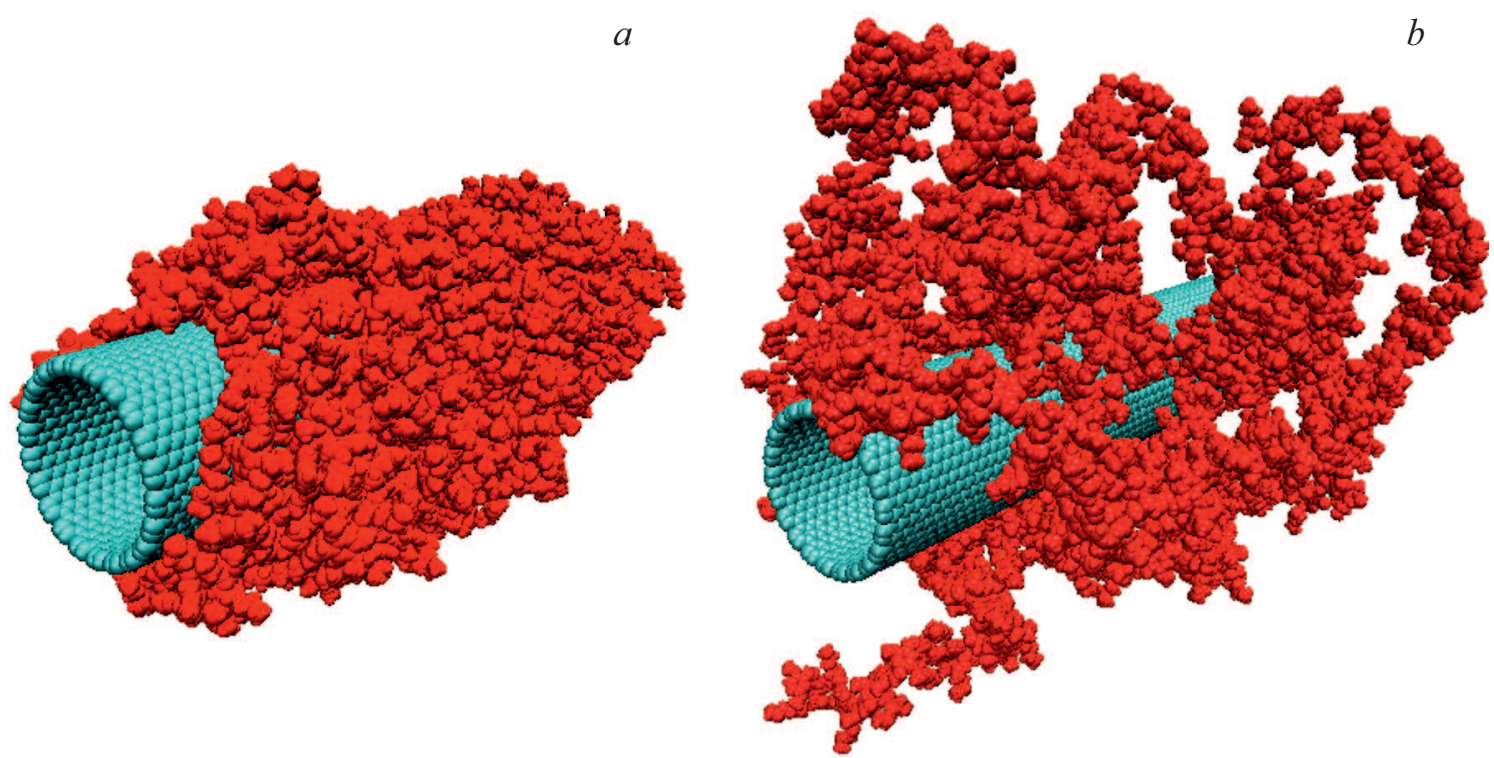

Рис. 6. Адсорбция макромолекулы MEH-PPV на поверхности углеродной нанотрубки в воде $(a)$ и в толуоле $(b)$.

также между двумя параллельно расположенными одностенными углеродными нанотрубками в толуоле. Длина углеродной нанотрубки составляла $15 \mathrm{~nm}$, а ее диаметр около $3 \mathrm{~nm}$, индексы хиральности $n=22$ и $m=22$. Атомы углеродной нанотрубки в процессе моделирования оставались зафиксированными. Вся молекулярная система была помещена в ячейку с периодическими граничными условиями, которая в одном случае заполнялась молекулами воды, а во всех остальных молекулами толуола, при этом число молекул толуола определялось исходя из плотности толуола в жидком состоянии.
МД моделирование производилось с использованием программного комплекса NAMD 2.13 [25] при постоянной температуре (термостат Берендсена) в течение нескольких десятков наносекунд: на начальном участке траектории температура устанавливалась равной $900 \mathrm{~K}$, а на конечном участке - $300 \mathrm{~K}$. Это позволяло достигать более глубоких минимумов конформационной энергии макроцепи, в том числе на более коротком участке траектории [26]. Для MEH-PPV и толуола использовалось силовое поле CHARMM General Force Field (CGenFF) [27,28]. Параметры для атомов углерода нанотрубки задавались такими же, как и для атомов типа $C A$ 

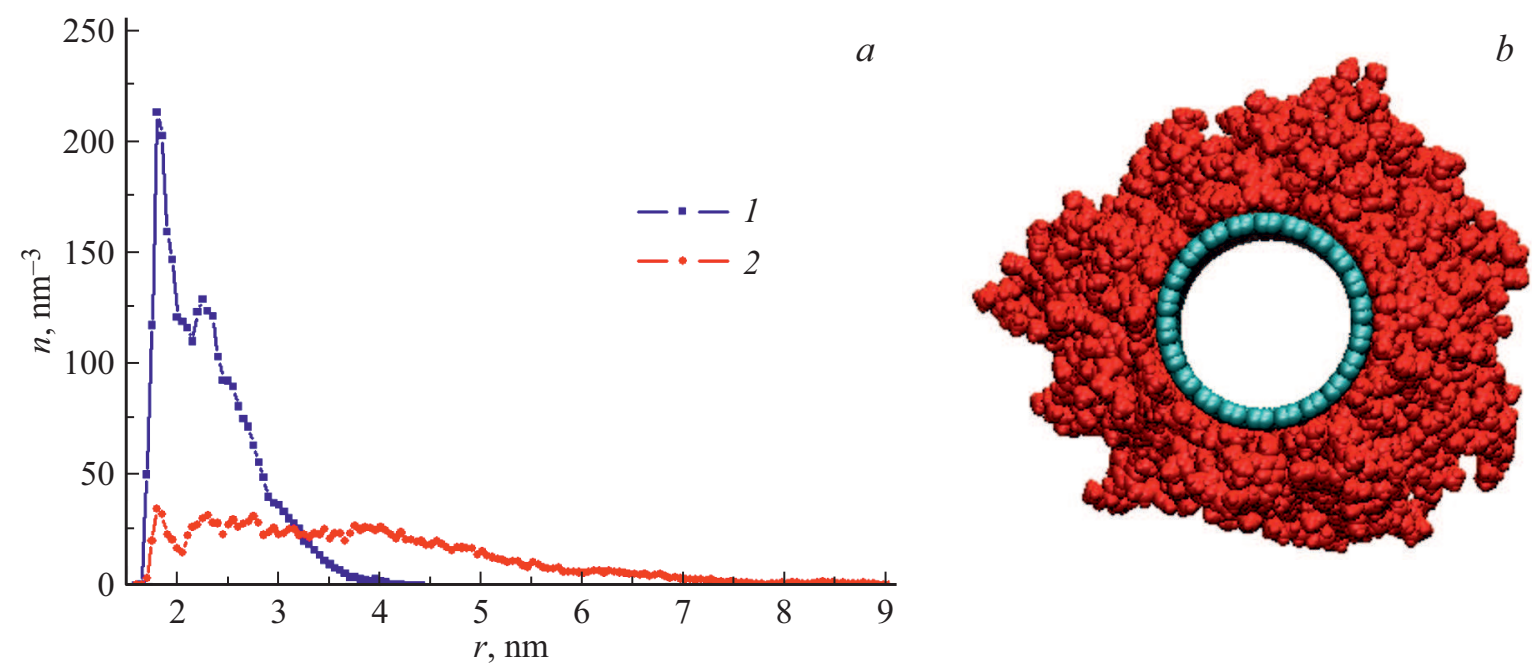

Рис. 7. Результат МД моделирования макромолекулярной опушки МЕН-PPV на УНТ: $a$ - радиальные зависимости средней концентрации атомов MEH-PPV на поверхности углеродной нанотрубки в воде (1) и толуоле (2); $b-$ структура сечения адсорбированной на УНТ опушки МЕН-PРV в воде.
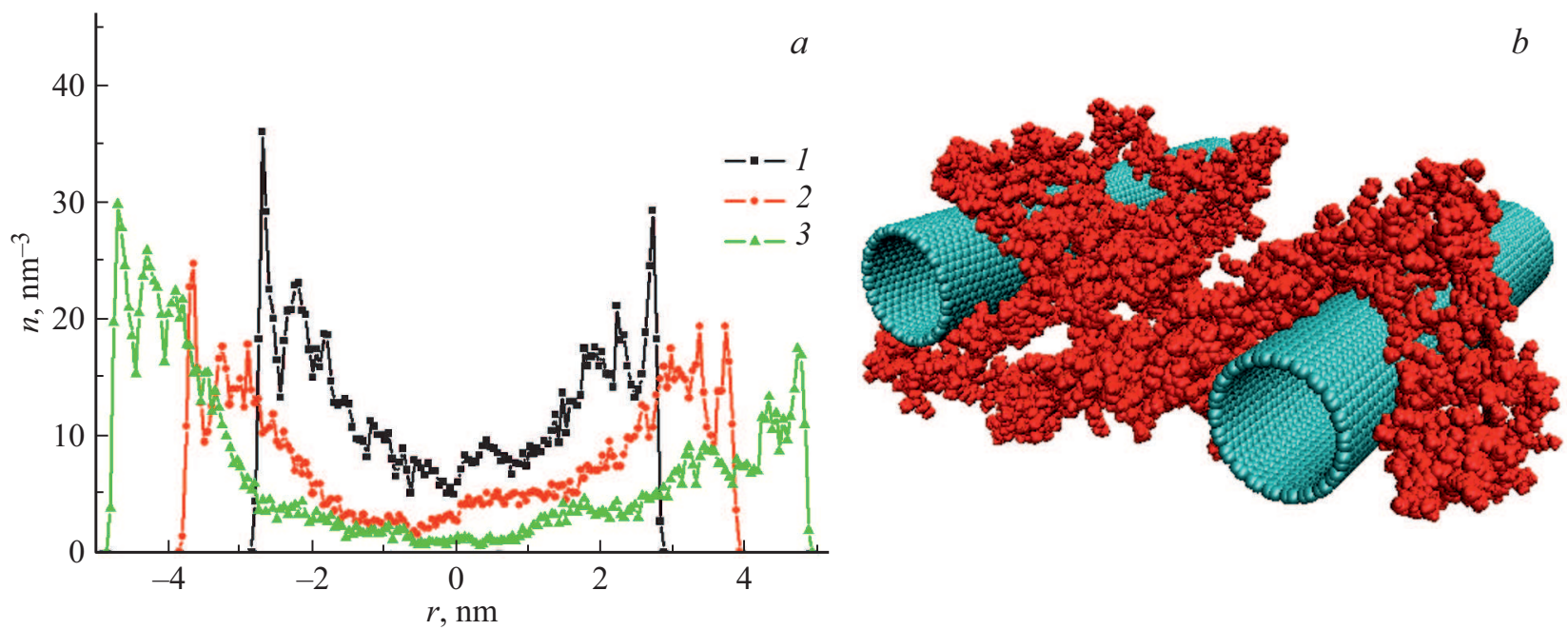

Рис. 8. Конформация макроцепи MЕН-PРV, адсорбированной на двух УНТ в толуоле: $a$ - радиальные зависимости концентрации атомов МЕН-PPV в области между УНТ при расстоянии между осями нанотрубок 9 (1), 11 (2) и $13 \mathrm{~nm}(3)$; $b-$ общий вид структуры макроцепи при расстоянии между осями нанотрубок $11 \mathrm{~nm}(8 \mathrm{~nm}$ между поверхностями УНТ).

силового поля CHARMM22 [29], которые используются для описания молекул бензола [30]. Потенциал Вандер-Ваальса обрезался на расстоянии $1.2 \mathrm{~nm}$ с помощью функции сглаживания между 1.0 и $1.2 \mathrm{~nm}$. Электростатические взаимодействия рассчитывались непосредственно на расстоянии $1.2 \mathrm{~nm}$, для больших дистанций использовался метод „частица-сетка“ Эвальда (PME) [31] с шагом сетки $0.11 \mathrm{~nm}$.

На рис. 6, $a$ изображена макромолекула MEH-PPV из 500 звеньев после МД-моделирования на поверхности углеродной нанотрубки в воде, а на рис. $6, b-$ в толуоле. Видно, что в воде макромолекула MEH-PPV полностью адсорбировалась на поверхности углеродной нанотрубки, а в толуоле макромолекулярная опушка стала рыхлой, и наблюдается появление значительных по размеру петель макроцепи, которые не адсорбировались на поверхности, что согласуется с плохой растворимостью MEH-PPV в воде и хорошей в толуоле. По результатам МД моделирования рассчитывались радиальные распределения концентрации атомов МЕНPPV на поверхности углеродной нанотрубки, а в случае моделирования с двумя нанотрубками по отдельности на поверхности каждой углеродной нанотрубки с последующим объединением кривых распределений посредине между нанотрубками.

На рис. 7, $a$ представлены радиальные зависимости средней концентрации атомов MEH-PPV на поверхности углеродной нанотрубки, полученные в результате МД моделирования в воде $(1)$ и толуоле (2). Аппроксимирующие эти зависимости кривые, построенные на осно- 
ве аналитических выражений (8)-(10), демонстрируют приемлемое совпадение с МД профилями. Из сравнения зависимостей 1 и 2 видно, что плотность атомов цепи MEH-PPV в воде (рис. 7, $b$ ) примерно в восемь раз выше, чем в толуоле, а эффективная толщина опушечного слоя больше в неполярном толуоле. Этот результат объясняется гидрофобными свойствами цепей полимера и УНТ.

Кроме того, было произведено МД моделирование конформационной структуры и адсорбции макромолекулы MEН-PPV на двух одностенных УНТ в толуоле. Углеродные нанотрубки длиной $15 \mathrm{~nm}$ и диаметром $3 \mathrm{~nm}$ располагались параллельно друг другу. Расстояние между осями нанотрубок составляло 9,11 или $13 \mathrm{~nm}$. Макромолекула в стартовой конфигурации располагалась между углеродными нанотрубками и была предварительно свернута в неравновесную клубковую структуру.

На рис. 8, $a$ представлены радиальные распределения средней концентрации атомов MEH-PPV в области между нанотрубками в зависимости от расстояния между их осями, а на рис. $8, b$ показан результат МД моделирования макромолекулы MEH-PPV длиной 500 звеньев в толуоле между двумя параллельными углеродными нанотрубками с расстоянием между осями нанотрубок $11 \mathrm{~nm}$. Максимумы радиальных зависимостей концентрации атомов отражают адсорбцию звеньев полимера на поверхности УНТ, поэтому из графиков рис. $8, a$ и $b$ видно, что макромолекула частично адсорбируется на поверхностях обеих нанотрубок. По мере увеличения расстояния между нанотрубками конформационная структрура MEH-PPV становится более рыхлой, наблюдается увеличение количества значительных по размеру петель макроцепи, „выброшенных“ в жидкую фазу раствора. Это связано с тем, что при удалении нанотрубок друг от друга более значимым становится влияние растворителя на конформационную структуру макроцепи, что и находит отражение на графиках радиальных распределений концентраций атомов MEH-PPV на рис. 8. Этот результат согласуется с фактом хорошей растворимости MEH-PPV в толуоле.

\section{Благодарности}

Авторы признательны Л.В. Грекову за помощь в проведении FDTD расчетов.

\section{Финансирование работы}

Исследование выполнено при финансовой поддержке Министерства науки и высшего образования Российской Федерации в рамках научного проекта № FSGU-20200003.

\section{Конфликт интересов}

Авторы заявляют, что у них нет конфликта интересов.

\section{Список литературы}

[1] Давиденко Н.А., Дехтлренко С.В., Козинеи А.В., Лобач А.С., Мокринская Е.В., Скрышевский В.А., Спицына Н.Г., Студзинский С.Л., Третяк О.В., Тонкопиева Л.С. // ЖТФ. 2011. Т. 81. В. 2. С. 103; Davidenko N.A., Dekhtyarenko S.V., Kozinets A.V., Lobach A.S., Mokrinskaya E.V., Skryshevsky V.A., Spitsyna N.G., Studzinsky S.L., Tretyak O.V., Tonkopieva L.S. // Technic. Phys. 2011. V. 56. P. 259.

[2] Bakulin A.A., Pshenichnikov M.S., van Loosdrecht P.H.M., Golovnin I.V., Paraschuk D.Y. // Physics of Nanostructured Solar Cells / Ed. by Badescu V., Paulescu M. Nova Science Publishers. 2010. P. 463-504.

[3] Sosorev A.Y., Parashchuk O.D., Zapunidi S.A., Kashtanov G.A., Paraschuk D.Y. // J. Phys. Chem. C. 2013. V. 117 (14). P. 6972. doi 10.1021/jp4000158

[4] Chambers D.K., Karanam S., Qi D., Selmic S., Losovyj Y.B., Rosa L.G., Dowben P.A. // Appl. Phys. A. 2005. V. 80. P. 483. doi 10.1007/s00339-004-3043-x

[5] Клочков А.Я., Максименко С.А., Масалов Е.И. // Изв. Юго-Западного государственного ун-та. Сер. Физика и химия. 2013. № 2. С. 50.

[6] Максименко С.A., Слепян Г.Я. // Радиотехн. и электрон. 2002. T. 47. № 3. C. 261; Maksimenko S.A., Slepyan G.Ya. // J. Commun. Technol. and Electronics. 2002. V. 47. N 3. P. 235-252.

[7] Kucherenko M.G., Stepanov V.N., Kruchinin N.Yu. // Opt. Spectrosc. 2015. V. 118. N 1. P. 103. doi 10.1134/S0030400X15010154

[8] Marocico C.A., Knoester J. // Phys. Rev. A. 2009. V. 79. P. 053816 (1-15). doi 10.1103/PhysRevA.79.053816

[9] Чмерева Т.М., Кучеренко М.Г. // Опт. и спектр. 2011. T. 110. № 5. C. 819; Chmereva T.M., Kucherenko M.G. // Opt. Spectrosc. 2011. V. 110. N 5. P. 767-774. doi 10.1134/S0030400X11040084

[10] Кучеренко М.Г., Чмерева Т.М. // Журн. прикл. спектр. 2017. T. 84. № 3. C. 358; Kucherenko M.G., Chmereva T.M. // J. Appl. Spectrosc. 2017. V. 84. N 3. doi 10.1007/s10812-0170480-9

[11] Kucherenko M.G., Nalbandyan V.M. // Phys. Proc. 2015. V. 73. P. 136. doi 10.1016/j.phpro. 2015.09.134.

[12] Чмерева Т.М., Кучеренко М.Г., Дмитриев А.Д. // Опт. и спектр. 2015. Т. 118. № 2. С. 300; Chmereva T.M., Kucherenko M.G., Dmitriev A.D. // Opt. Spectrosc. 2015. V. 118. N 2. P. 284-289. doi 10.7868/S0030403415020051

[13] Hernández-Martínez P.L., Govorov A.O. // Phys. Rev. B. 2008. V. 78. P. 035314. doi 10.1103/PhysRevB.78.035314

[14] Hernaández-Martínez P.L., Govorov A.O. // J. Phys. Chem. C. 2013. doi 10.1021/jp402242y

[15] Klimov V.V., Ducloy M. // arXiv:physics/0206048v2 [physics.atom-ph] 20 Dec 2002.

[16] Гросберг А.Ю., Хохлов А.Р. Статистическая физика макромолекул. М.: Наука, 1989. 344 с.

[17] Кучеренко М.Г., Чмерева Т.М. // Вестник ОГУ. 2008. № 9. C. 177.

[18] Klimov V.V., Ducloy M. // Phys. Rev. A. 2000. V. 62. P. 043818. doi 10.1103/PhysRevA.62.043818

[19] Jung Y.W., Byun L.S.Y.H., Kim Y.D. // Synthetic Metals. 2010. V. 160. P. 651. 
[20] Marletta A., Gonçalves V, Balogh D.T. // Brazilian J. Phys. 2004. V. 34. N 2B. P. 697. doi 10.1590/S010397332004000400048

[21] Qian H., Carsten G., Anderson N. // Basic Sol. Stat. Phys. J. (b). 2008. V. 245. P. 2243. doi 10.1002/pssb.200879598

[22] Климов В.В., Дюклуа М., Летохов В.С. // Квант. электрон. 2001. T. 31. № 7. C. 569; Klimov V.V., Ducloy M., Letokhov V.S. // Quant. Electron. 2001. V. 31(7). P. 569. doi 10.1070/QE2001v031n07ABEH002007 www.mathnet.ru/ links/c464e6d35313e05b9ea714fe9920223f/ qe2007.pdf

[23] Bondarev I.V., Woods L.M., Popescu A. // Opt. Spectrosc. 2011. V. 111. N 5. P. 733. doi 10.1134/S0030400X11120046

[24] Tan P.H., Rozhin A.G., Hasan T., Hu P., Scardaci V., Milne W.I., Ferrari A.C. // Phys. Rev. Lett. 2007. V. 99. P. 137402(4). doi 10.1103/PhysRevLett.99.137402

[25] Phillips J.C., Braun R., Wang W., Gumbart J., Tajkhorshid E., Villa E., Chipot C., Skeel R.D., Kale L., Schulten K. // J. Comput. Chem. 2005. V. 26. P. 1781. doi 10.1002/jcc.20289

[26] Кручинин Н.Ю., Кучеренко М.Г. // Коллоид. журн. 2020. T. 82. № 2. C. 177; Kruchinin N.Yu., Kucherenko M.G. // Colloid. J. 2020. doi 10.31857/S0023291220020081

[27] Vanommeslaeghe K., Hatcher E., Acharya C., Kundu S., Zhong S., Shim J., Darian E., Guvench O., Lopes P., Vorobyov I., MacKerell A.D. Jr. // J. Comput. Chem. 2010. V. 31. P. 671. doi 10.1002/jcc. 21367

[28] Yu W., He X., Vanommeslaeghe K., MacKerell A.D. Jr. // J. Comput. Chem. 2012. V. 33. P. 2451. doi $10.1002 /$ jcc.23067

[29] MacKerell A.D. Jr., Bashford D., Bellott M., Dunbrack R.L. Jr., Evanseck J.D., Field M.J., Fischer S., Gao J., Guo H., Ha S., Joseph-McCarthy D., Kuchnir, Kuczera K., Lau F.T.K., Mattos C., Michnick S., Ngo T., Nguyen L., Prodhom B., Reiher W.E. III, Roux B., Schlenkrich M., Smith J.C., Stote R., Straub J., Watanabe M., WiorkiewiczKuczera J., Yin D., Karplus M. // J. Phys. Chem. B. 1998. V. 102. P. 3586. doi $10.1021 /$ jz500054d

[30] Zhu F., Schulten K. // Biophys. J. 2003. V. 85. P. 236. doi 10.1016/S0006-3495(03)74469-5

[31] Darden T., York D., Pedersen L. // J. Chem. Phys. 1993. V. 98. P. 10089. doi 10.1063/1.464397 